CZASOPISMO INŻYNIERII LĄDOWEJ, ŚRODOWISKA I ARCHITEKTURY JOURNAL OF CIVIL ENGINEERING, ENVIRONMENT AND ARCHITECTURE

JCEEA, t. XXXIII, z. 63 (4/16), październik-grudzień 2016, s. 607-615

\author{
Ewa SOBCZYŃSKA ${ }^{1}$ \\ Kacper WASILEWSKI ${ }^{2}$ \\ Martyna GREGORIOU-SZCZEPANIAK ${ }^{3}$
}

\title{
PROBLEMATYKA MODELOWANIA KONSTRUKCJI MUROWYCH NA PRZYKLADZIE KAMIENICY PRZY ULICY SZAREJ W WARSZAWIE
}

\begin{abstract}
W poniższej pracy zwrócono uwagę na szczególne znaczenie analizy konstrukcji w działaniach rewitalizacyjnych dotyczących obiektów zabytkowych będącej jednym z najważniejszych aspektów zrównoważonego budownictwa w dzisiejszych czasach. Zaprezentowano różne strategie wykorzystywane $\mathrm{w}$ analizie konstrukcji murowych z wykorzystaniem metody elementów skończonych (MES) - mikro i makro-modelowanie oraz stosowane metody homogenizacji stosowane dla kompozytów, do których zaliczamy mury. W celu zaprezentowania specyfiki analizy konstrukcji murowych stworzono makro-model nadproża murowego będącym fragmentem wielorodzinnego budynku mieszkalnego zlokalizowanego przy ul. Szarej $10 \mathrm{w}$ Warszawie. Wartości parametrów mechanicznych materiału przyjętego do analizy numerycznej (moduł Younga oraz współczynnik Poissona) zostały ustalone $\mathrm{z}$ wykorzystaniem wybranych metod homogenizacji murów- Mieczysława Kuczmy i Krystyny Wybranowskiej oraz J. Lopeza, S. Ollera, E. Onate i J. Lublinera. Stosując powyższe założenia stworzono model fragmentu analizowanej ściany zawierającej analizowane nadproże i przeprowadzono analizę z wykorzystaniem programu ABAQUS, której wyniki zostały przedstawione w postaci map naprężeń oraz odkształceń plastycznych analizowanego fragmentu oraz porównania rzeczywistego zarysowania istniejącej konstrukcji $\mathrm{z}$ zarysowaniem otrzymanym w analizie numerycznej. W końcowych wnioskach sformułowano i omówiono specyfikę modelowania konstrukcji murowych, ze szczególnym zwróceniem uwagi na problemy jemu towarzyszące. Przede wszystkim skoncentrowano się na licznych niewiadomych towarzyszących od początku tworzenia modelu, które wymagają poczynienia licznych założeń i przybliżeń oraz na konieczności ostrożnego podejścia do otrzymanych wyników.
\end{abstract}

Słowa kluczowe: konstrukcje murowe, modelowanie numeryczne, homogenizacja, zarysowanie

\footnotetext{
1 Autor do korespondencji / corresponding author: Ewa Sobczyńska, Politechnika Warszawska, Zespół Budownictwa Ogólnego i Zrównoważonego Rozwoju, Al. Armii Ludowej 16, 00-637 Warszawa; tel. 694074563; esob@il.pw.edu.pl

${ }^{2}$ Kacper Wasilewski, Politechnika Warszawska

3 Martyna Gregoriou-Szczepaniak, Politechnika Warszawska
} 


\section{Wstęp}

Działania mające na celu modernizację, adaptację lub naprawę istniejących obiektów budowlanych należą obecnie do grona najważniejszych zadań realizowanych $\mathrm{w}$ ramach zagadnień związanych ze zrównoważonym rozwojem w budownictwie. W szczególności dotyczy to obiektów, także zabytkowych, znajdujących się na obszarach kryzysowych, będących przedmiotem programów rewitalizacji [1]. Spośród wielu działań rewitalizacyjnych dotyczących budynków istotny element stanowi rehabilitacja ich konstrukcji. W przypadku istniejących budynków, zwłaszcza zabytkowych mamy zwykle do czynienia z technologią tradycyjną - murowaną, w której ściany wykonane są z cegły ceramicznej na zaprawie wapiennej, wapienno-cementowej lub cementowej. W celu prawidłowego przeprowadzenia rehabilitacji konstrukcji murowych należy zawsze poprzedzić ją właściwą diagnostyką, w wyniku której określony zostanie stan techniczny konstrukcji, a także przyczyny zaistniałych uszkodzeń [2][3]. W tym celu bardzo często wykorzystywane jest obecnie narzędzie modelowania numerycznego.

\section{Modelowanie numeryczne konstrukcji murowych}

Mur jako materiał złożony z elementu murowego oraz zaprawy należy do materiałów kompozytowych, którego właściwości ściśle zależą od właściwości i współpracy tych dwóch składników.

W modelowaniu numerycznym konstrukcji murowych za pomocą Metody Elementów Skończonych (MES) można wyróżnić dwa generalne podejścia jedno zorientowane na oddzielnym modelowaniu poszczególnych składników muru oraz drugie, w którym mur modeluje się jako kompozyt [5][6]. W pierwszej metodzie, nazywanej mikro-modelowaniem lub modelowanie heterogenicznym, można zastosować dwa stopnie szczegółowości. W szczegółowym mikromodelu (Rys. 1a) należy ustalić moduł Younga, współczynnik Poissona i ewentualne charakterystyki nieliniowe oddzielnie dla elementów murowych oraz zaprawy. Ponadto należy zamodelować powierzchnię styku (interfejs), która będzie reprezentował zjawiska zachodzące pomiędzy materiałami. W uproszczonym mikromodelu (Rys. 1b) połączenia pomiędzy elementami i zaprawą oraz zaprawa sprowadzone są do pojedynczego interfejsu, a elementy murowe powiększone w taki sposób aby geometria konstrukcji pozostała niezmieniona. Tego typu rozwiązanie w znaczny sposób upraszcza i przyspiesza obliczenia jednak odbywa się to kosztem szczegółowości analizy. W drugiej metodzie (Rys. 1c), nazywanej makro-modelowaniem lub homogenicznym modelowaniem fenomenologicznym [5], materiał sprowadzony jest do homogenicznego materiału anizotropowego, nie uwzględniając podziału na składniki, zaprawę i elementy murowe. Właściwości mechaniczne w tej metodzie mogą być ustalone doświadczalnie, przez badanie całej konstrukcji murowej, lub za pomocą homogenizacji na podstawie właściwości mechanicznych elementów murowych i zaprawy oraz układu elementów w murze. 
Każda z wymienionych powyżej metod modelowania jest odpowiednia do innego zastosowania. Wraz ze wzrostem szczegółowości modelu wzrasta dokładność obliczeń, co przekłada się bezpośrednio na czas trwania obliczeń oraz na konieczność ustalenia dodatkowych parametrów materiałowych. Mikromodelowanie może być wykorzystywane do szczegółowej analizy lokalnych zachowań elementów murowych w niedużych fragmentach konstrukcji, natomiast makro-modelowanie wykorzystywane jest do zadań inżynierskich, na przykład gdy przeprowadza się analizę całego budynku.

W dalszej części pracy przedstawiono homogeniczny makromodel fragmentu istniejącego budynku murowanego.

a)

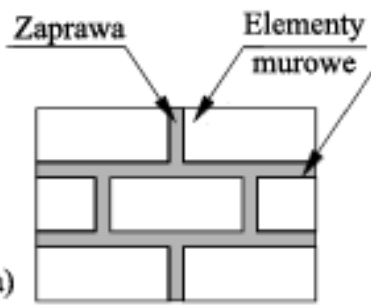

b)

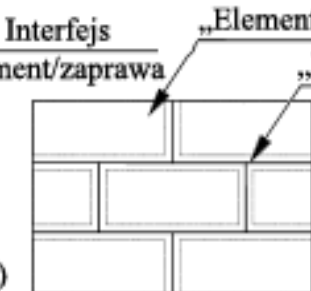

c)

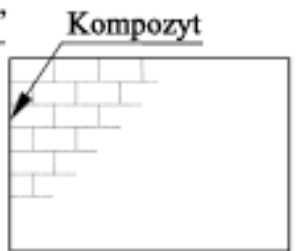

Rys. 1. Sposoby modelowania konstrukcji murowych: a) szczegółowy mikro-model, b) uproszczony mikro-model i c) makro-model, na podstawie [4]

Fig. 1. Methods of modeling of masonry structures: a) detailed micro-model, b) simplified micro-model and c) macro-model, based on [4]

\section{Przedstawienie obiektu i analizowanego obszaru}

Analizowany obiekt to wielorodzinny budynek mieszkalny zlokalizowany przy ul. Szarej 10 w Warszawie. Budynek został zbudowany ok. 1908-1911, należał do Starokatolickiego Kościoła Mariawitów i stanowił część kompleksu ze stojącym w pobliżu kościołem pod wezwaniem Przenajświętszego Sakramentu. Pełnił funkcję mieszkalną dla członków parafii i mieścił szkołę elementarną.

Pierwotnie, przed wojną budynek, posiadał dwa skrzydła prostopadłe do ulicy Szarej, z których do dzisiaj zachowało się tylko jedno- prostopadłe do ulicy Szarej. Do wzniesienia budynku wykorzystano technologię tradycyjną - mury z cegły ceramicznej pełnej o wymiarach $27 \times 13 \times 6,5 \mathrm{~cm}$ na zaprawie wapiennej. Budynek jest podpiwniczony, ma pięć kondygnacji nadziemnych o wysokości ok.3,6 m oraz poddasze użytkowe. Ustrój nośny budynku stanowią ściany podłużne.

W dalszej części pracy przedstawiono analizę numeryczną zewnętrznej, południowo-zachodniej ściany budynku (Rys. 2). Ściana ma grubość $77 \mathrm{~cm} \mathrm{z} \mathrm{licz-}$ nymi wnękami [10]. 


\subsection{Właściwości mechaniczne}

W celu ustalenia właściwości mechanicznych materiału przyjętego do analizy numerycznej zastosowano dwa modele homogenizacji: Mieczysława Kuczmy i Krystyny Wybranowskiej oraz J. Lopeza, S. Ollera, E. Onate i J. Lublinera [8][9]. Trudność napotkano jednak w ustaleniu parametrów mechanicznych cegieł i zaprawy z których wykonano analizowany mur. Przyjęto cegły klasy 15. Na podstawie dostępnej literatury [6] określono, że wartości modułu sprężystości cegieł mieszczą się w granicach od 7500 do 15000 [MPa], a w przypadku analizowanych cegieł, biorąc pod uwagę ich średnią wytrzymałość, przyjęto wartość 9000 [MPa] oraz założono izotropową strukturę cegieł. Wartość modułu Younga zaprawy na podstawie literatury [7] założono w granicach 400 do 800 [MPa]. Wartości przyjętych modułów sprężystości i współczynników Poissona zaprezentowano w Tab. 1.

Tabela 1. Przyjęte wartości modułu Younga i współczynnika Poissona

Table 1. The values of Young's modulus and Poisson's ratio

\begin{tabular}{|l|c|c|c|}
\hline \multicolumn{2}{|c|}{ Charakterystyka } & Zaprawa & Cegła \\
\hline \multirow{3}{*}{ Moduł Younga } & Kierunek X & $\mathrm{E}_{\mathrm{xM}}=800 \mathrm{MPa}$ & $\begin{array}{c}\mathrm{E}_{\mathrm{xL}}=E_{x L L}=9000 \\
\mathrm{MPa}\end{array}$ \\
\cline { 2 - 4 } & Kierunek Y & $E_{y M_{1}}==800$ & $\begin{array}{c}\mathrm{E}_{\mathrm{yL}}=\boldsymbol{E}_{y L}=9000 \\
\mathrm{MPa}\end{array}$ \\
& $\begin{array}{c}\mathrm{MPa} \\
\text { Współczynnik Poissona }\end{array}$ & $v_{\mathrm{M} 2}=0,167$ \\
\hline \multicolumn{2}{|l}{} \\
\hline
\end{tabular}

Na postawie przyjętych powyżej parametrów oraz metody Mieczysława Kuczmy i Krystyny Wybranowskiej [8]określono wartości zhomogenizowanych parametrów mechanicznych modelowanego ośrodka murowego. Uzyskane wartości zaprezentowano w Tab. 2.

Tabela 2. Zestawienie wyników uzyskanych z przeprowadzonej analizy

Table 2. Summary results obtained from the analysis

\begin{tabular}{|c|c|}
\hline$v_{X}=v_{Y}$ & 0,167 \\
\hline$E_{X}$ & $6050[\mathrm{MPa}]$ \\
\hline$E_{Y}$ & $4100[\mathrm{MPa}]$ \\
\hline $\mathrm{G}_{X Y}$ & $2600[\mathrm{MPa}]$ \\
\hline
\end{tabular}

Warto porównać uzyskane wielkości z wartościami wyliczonymi z modelu J. Lopeza, S. Ollera, E. Onate i J. Lublinera. Według tego modelu [9] moduł sprężystości podłużnej $\mathrm{w}$ kierunku $\mathrm{X}$ wynosi $\mathrm{E}_{\mathrm{XG}}=5790,95$ [MPa], a moduł sprężystości $\mathrm{w}$ kierunku $\mathrm{Y}_{\mathrm{YG}}=3827,93$ [MPa]. Wielkości te są zbliżone do uzyskanych z pierwszego modelu (błąd nie przekracza 4,5\%). Wartości wykorzystane do wykonania modelu i analizy numerycznej przedstawiono w Tab. 3. 
Tabela 3. Parametry przyjęte do modelowania

Table 3. The parameters adopted for modeling

\begin{tabular}{|c|c|}
\hline $\mathrm{E}$ & $5075[\mathrm{MPa}]$ \\
\hline $\boldsymbol{v}$ & 0,167 \\
\hline
\end{tabular}

\subsection{Prezentacja modelu i wyników}

Model fragmentu elewacji południowo-zachodniej (Rys. 4) budynku oznaczono na Rys. 3. W modelu uwzględniono także zamurowane obecnie fragmenty uszkodzonej ściany murowej aby zaprezentować ich ewentualny wpływ na kształt powstałych zarysowań.

Do modelowania wykorzystano dostępny w programie ABAQUS model materiału Concrete $\mathrm{z}$ zaimplementowanym mechanizmem opisu spękań wg rys rozmytych (ang. smeared cracks) dla materiałów kruchych. Ponadto pozwala on na opis zachowania materiału w sposób nieliniowy, co jest istotne w przypadku modelowania konstrukcji murowych. Ograniczenie stanowi brak możliwości opisu jego ortotropii.

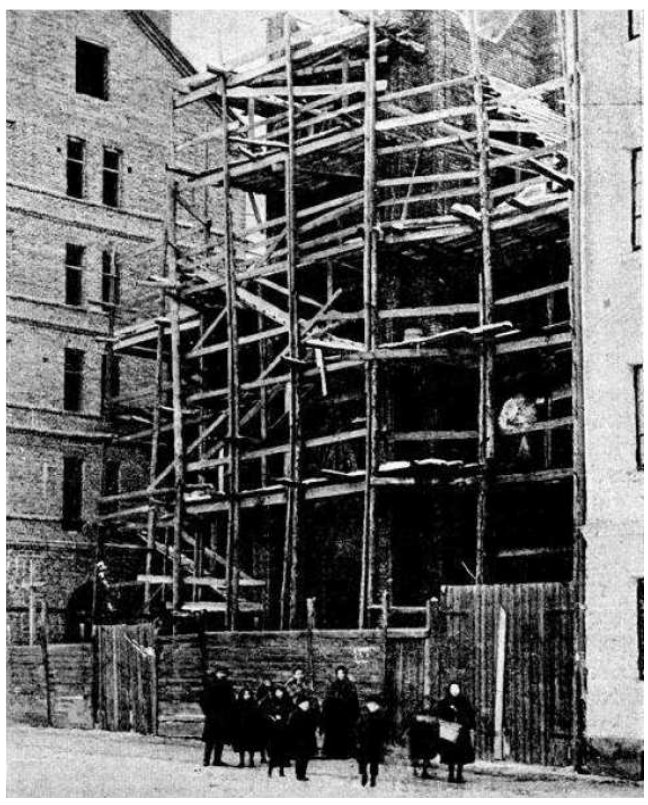

Rys. 2. Budynek przy ul. Szarej 10 w Warszawie w trakcie budowy (r.1911) [10]

Fig. 2. Building at Szara Street 10 in Warsaw under construction (1911) ) [10]

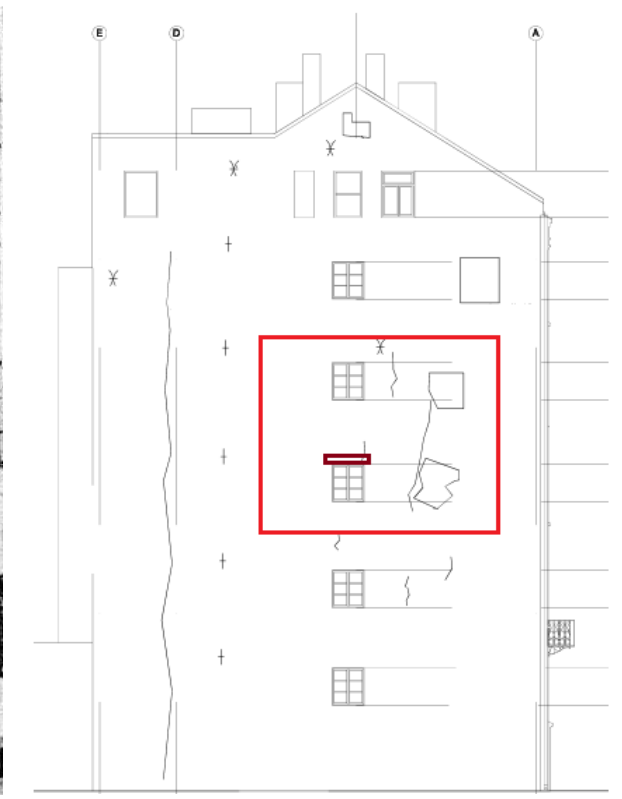

Rys. 3. Elewacja południowo-zachodnia z zaznaczonym modelowanym fragmentem ściany i nadprożem

Fig. 3. South-western elevation with selected part of the wall and lintel 
Gdy dominującym stanem naprężeń jest ściskanie, zachowanie muru opisano jako sprężysto-plastyczne, a jego charakterystyki zdefiniowane są za pomocą dwóch parametrów: współczynnika sprężystości podłużnej E oraz współczynnika Poissona v (Tab. 3).

Ścianę zamocowano odbierając jej przesuw i obrót na dole modelowanego fragmentu. Obciążono ją w poziomie stropów (wartość obciążenia obliczono na $150 \mathrm{kN} / \mathrm{m}$ ) oraz zadano obciążenie ciężarem własnym. Na Rys. 5 przedstawiono rozkład naprężeń dla modelowanego fragmentu. W celu określenia czy w danym modelu powstają zarysowania należy przedstawić mapy rozkładu głównych odkształceń plastycznych. Rozciągające odkształcenia plastyczne należy interpretować jak miejsca pojawienia się zarysowania (Rys. 6).

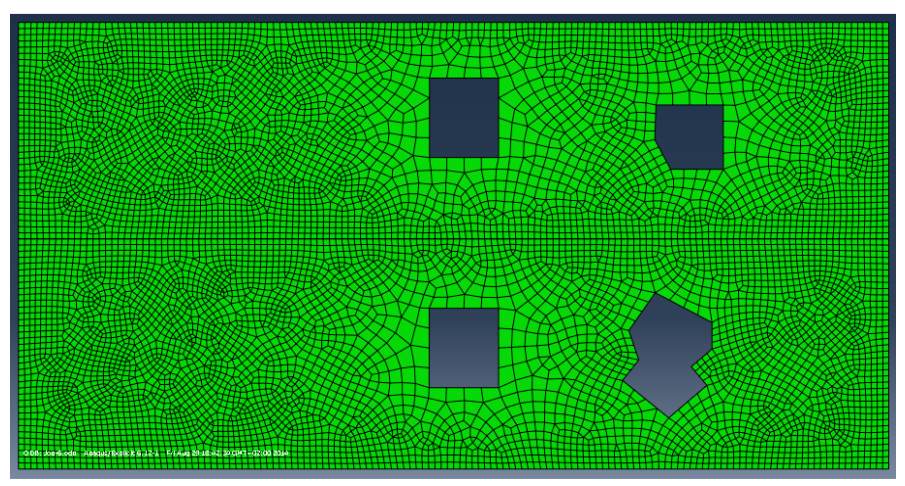

Rys. 4. Model fragmentu elewacji

Fig. 4. Model of the part of the elevation

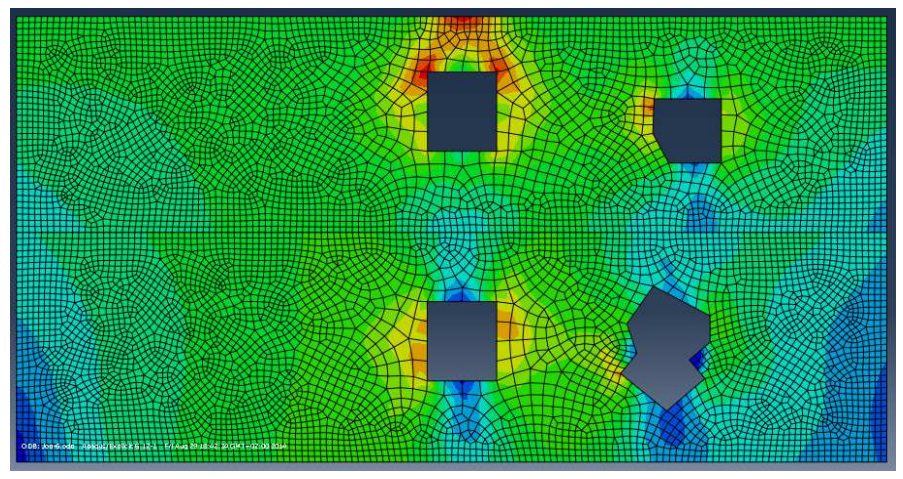

Rys. 5. Rozkład naprężeń zredukowanych Misesa

Fig. 5. Reduced Mises stresses distribution 


\subsection{Interpretacja wyników analizy numerycznej}

Analizując mapę głównych odkształceń plastycznych (Rys. 6) możemy zauważyć, ze miejsca pojawienia się zarysowania to na pewno obszary w pobliżu najbardziej nieregularnego otworu co zgadza się z zarysowaniami zaobserwowanymi na budynku (obszar 1, Rys. 7). Ponadto widoczne są obszary o nieco mniejszych ale istniejących odkształceniach plastycznych zlokalizowane pomiędzy otworami na niższej z zamodelowanych kondygnacji (obszar 2, Rys. 7). Granica tego obszaru pokrywa się z rysą w nadprożu. Możliwym jest więc, że zarysowanie te powstało $\mathrm{w}$ wyniku działania obciążeń statycznych. $\mathrm{Z}$ uwagi na fakt, że w modelu numerycznym nie otrzymano wszystkich istniejących na analizowanej ścianie zarysowań, przyjąć można przypuszczać, że istnieje inna przyczyna ich powstania, którą mogły być na przykład wybuchy albo pożar kościoła w pobliżu budynku.

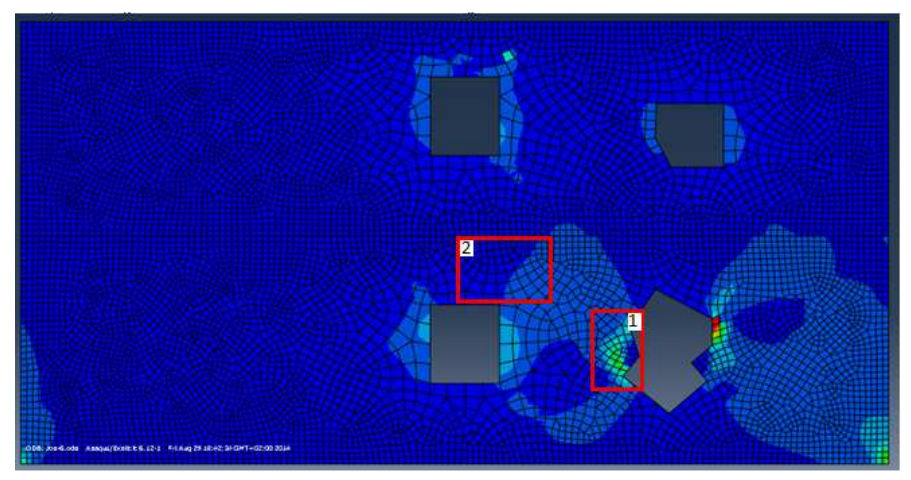

Rys. 6. Mapy głównych odkształceń plastycznych dla materiału Concrete

Fig. 6. Maps of the main plastic deformation for the Concrete material

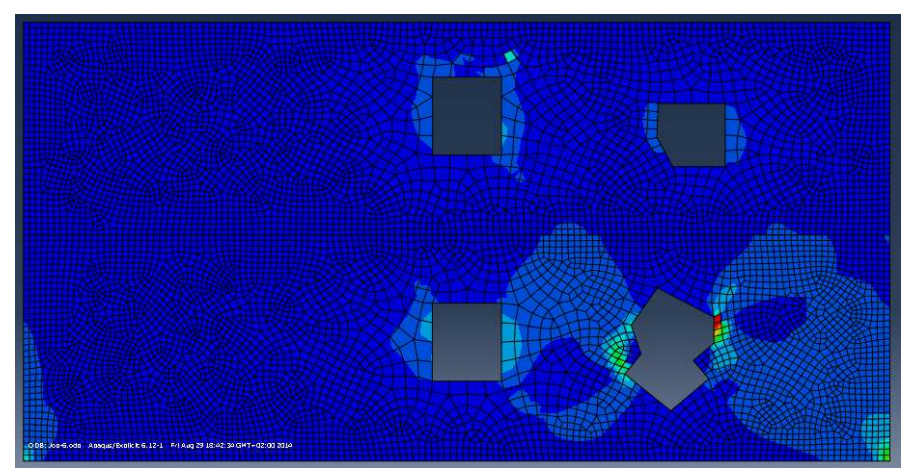

Rys. 7. Obszary zarysowań na analizowanym fragmencie ściany

Fig. 7. Areas of scratches on the analyzed part of the wall 


\section{Wnioski}

Modelowanie numeryczne konstrukcji murowych jest tematem złożonym, skomplikowanym i w wielu przypadkach trudnym do zweryfikowania. Najistotniejszą kwestią jest szereg niewiadomych dotyczących istniejących konstrukcji, które wymuszają liczne przybliżenia. W wielu przypadkach, zwłaszcza gdy mamy do czynienia $\mathrm{z}$ obiektami zabytkowymi, niemożliwe jest pobranie próbek materiału z konstrukcji w celu określenia parametrów mechanicznych, czy nawet dokonanie szczegółowych badani morfologicznych. Wymusza to szacowanie wartości w oparciu o dostępną literaturę oraz o wiedzę dotyczącą technologii wykonywania konstrukcji, co w znacznym stopniu wpływa na wyniki analizy. Dotyczy to nie tylko wartości właściwości mechanicznych, ale również struktury muru oraz przyjętych warunków brzegowych modelu.

Kolejnym aspektem, który ma znaczący wpływ na modelowanie i wyniki analizy jest historia i aktualny stan konstrukcji. Zarówno elementy murowe jak i zaprawa są materiałami o właściwościach zmieniających się w czasie, często spotykane są ich ubytki lub skruszenie co wpływa na ich parametry fizyczne i wytrzymałościowe. Bardzo skomplikowanym zagadnieniem jest uwzględnienie w modelu numerycznym wpływu na konstrukcję oddziaływań wyjątkowych, takich jak pożary czy wybuchy w bezpośrednim sąsiedztwie.

Wybór odpowiedniej strategii przy analizie za pomocą MES jest także istotnym czynnikiem wpływającym na dokładność wyników. Najdokładniejsze wyniki uzyskać można przez zastosowaniu szczegółowego mikro-modelu, jednak tego typu podejście wymaga nie tylko szczegółowych badań w celu ustalenia licznych właściwości mechanicznych materiału, ale także bardzo dużej mocy obliczeniowej w celu przeprowadzenia obliczeń. W związku z tym przy analizie większych modeli, takich jak duże fragmenty lub całe obiekty budowlane wykorzystuje się makro-modelowanie, co nie pozostaje bez wpływu na szczegółowość wyników.

Modelowanie konstrukcji murowych jest dziedziną wciąż rozwijającą się, jednak liczne modele i badania muszą zostać jeszcze wykonane aby wyniki były jak najbardziej zbliżone do rzeczywistości.

\section{Literatura}

[1] Terlikowski W.: Rewitalizacja budynków użyteczności publicznej zgodnie z zasadami zrównoważonego rozwoju, Miesięcznik Materiały Budowlane 5’2013 (nr 489), Warszawa 2013.

[2] Terlikowski W.: Rola badań w procesie rewitalizacji budynków zabytkowych, Miesięcznik Materiały Budowlane 8’ 2013 (nr 492), Warszawa 2013.

[3] Terlikowski W.: Diagnozowanie konstrukcji budynków zabytkowych pod kątem ich adaptacji do współczesnych wymagań konstrukcyjno-użytkowych i zmiany funkcji, Czasopismo Materiały Budowlane 9' 2013, Warszawa 2013. 
[4] Lourenço P.: Recent Advances In Masonry Modelling: Micromodelling And Homogenisation, 14th International Brick and Block Masonry Conference, Australia, 2008.

[5] Jemioło S., Małyszko L.: MES i modelowanie konstytutywne w analizie zniszczenia konstrukcji murowych T.1.,Wydawnictwo Uniwersytetu Warmińsko-Mazurskiego, Olsztyn 2013.

[6] Małyszko L., Orłowicz R.: Konstrukcje murowe. Zarysowania i naprawy, Wydawnictwo UWM, Olsztyn 2000.

[7] Sieczkowski J., Szkołomicki J.: Określanie wytrzymałości złożonych konstrukcji murowych, Konferencja Naukowo-Techniczna. Konserwacje, wzmacnianie i modernizacja budowlanych obiektów historycznych i współczesnych, Kielce 2001.

[8] Kuczma M., Wybranowska K... Numerical homogenization of elastic brick masonry, Civil and Environmental Engineering Reports T.1, 2005, s. 135-152.

[9] Lopez J., Oller S., Onate E., Lubiner J.: A homogeneous constitutive model for masonry, Numerical Methods in Engineering, 1999.

[10] Bukowski M., Kalinowski M., Terlikowski W.: Ekspertyza techniczna stanu technicznego budynku mieszkalnego wielorodzinnego przy ul. Szarej $10 \mathrm{w}$ Warszawie.

\section{ISSUES OF MODELING OF MASONRY SRUCTURES: CASE STUDY OF TENEMENT HOUSE AT SZARA STREET IN WARSAW}

\section{S u m m a r y}

This paper highlights the particular importance of structural analysis in the revitalization of historical buildings, which is one of the most important aspects of sustainable development of buildings. Different strategies in the analysis of masonry structures using finite element method (FEM) were presented - micro and macro-modelling together with homogenization methods used for composites such as masonry. In order to show the issues of the analysis of masonry structures authors present a macro-model of masonry lintel which is a part of a multi-family dwelling building at Szara street in Warsaw. The values of mechanical parameters of material adopted for numerical analysis (Young's modulus and Poisson's ratio) were determined using the selected methods of homogenization of masonry - Mieczyslaw Kuchma and Krystyna Wybranowska and J. Lopez, S. Oller, J. and E. Onate Lubliner. Using those assumptions, the model of the analyzed part of the wall containing the lintel was developed. The analysis were performed using the ABAQUS program and the results were presented as maps of stresses and plastic deformation of the analyzed part as well as correlation studies of existing cracks with those received in numerical analysis. In the final conclusions issues of masonry structures modelling were formulated and discussed. Mainly focused on the many unknowns, which appears from the beginning of creation of the model what requires making some assumptions and approximations and result with need of cautious approach to the results.

Keywords: masonry structures, numerical modeling, homogenization, cracks

DOI:10.7862/rb.2016.305

Przestano do redakcji: 08.12.2016 $r$.

Przyjęto do druku: 20.12.2016 r. 